\title{
Spremljanje čustvenih izrazov v terapevtskem procesu: priredba kodirnega sistema SPAFF (Specific Affect Coding System)
}

\author{
Tomaž Erzar*, Tatjana Rožič, Katarina Kompan Erzar, Boštjan Čampa in Vesna Mirt Čampa
} Teološka fakulteta Univerza v Ljubljani

Povzetek: V članku predstavljamo za spremljanje terapevtskega procesa prirejeni sistem za kodiranje čustvenih izrazov, povzet po sistemu Specific Affect Coding System (SPAFF, Gottman in Coan, 2007). Predstavljena je kratka zgodovina in problemi kodiranja čustvenih izrazov, kode sistema, postopek kodiranja, usposabljanje ocenjevalcev ter pravila dobrega kodiranja. Prav tako so predstavljene izkušnje kodiranja z novim sistemom, razlogi za priredbe kod v kontekstu ocenjevanja terapevtskih procesov in predlogi za nadaljnje izboljšave.

Ključne besede: kodirni sistem SPAFF, čustva, psihoterapija, priredba testa, usposabljanje.

\section{Adaptation of the Specific Affect Coding System (SPAFF)}

Tomaž Erzar, Tatjana Rožič, Katarina Kompan Erzar, Boštjan Čampa, and Vesna Mirt Čampa Faculty of Theology, University of Ljubljana, Slovenia

\begin{abstract}
The article describes the Slovenian adaptation of the Specific Affect Coding System (SPAFF) which was developed by Gottman and colleagues (Gottman and Coan, 2007) for the purpose of examining emotional expression. We present a short history and problems of coding emotions, codes of the system, coding procedure, training of coders, and rules of accurate observing. Also presented are the experiences with the new system, arguments for adaptation of codes to therapeutic processes and suggestions for further improvements.
\end{abstract}

Key words: Specific Affect Coding System (SPAFF), emotions, psychotherapy, test adaptation, training

\footnotetext{
"Naslov/Address: dr. Tomaž Erzar, Teološka fakulteta, Univerza v Ljubljani, Poljanska cesta 4, 1000 Ljubljana, e-naslov: tomaz.erzar@ guest.arnes.si.

Članek je licenciran pod pogoji Creative Commons Attribution 4.0 International licence. (CC-BY licenca).

The article is licensed under a Creative Commons Attribution 4.0 International License (CC-BY license).
} 
Čustveni izrazi in njihove spremembe pričajo o notranjem doživljanju oseb $\mathrm{v}$ terapiji. Na terapevtskih srečanjih se klienti in terapevti povežejo prek čustvenih izrazov in jih s tem tudi spreminjajo. Za razumevanje terapevtskega procesa je pomembno, da spremembe $\mathrm{v}$ čustvovanju prepoznamo in jim sledimo iz trenutka v trenutek (Stern, 2004). Še zlasti je pomembno, da poskušamo zaznati spremembe $\mathrm{v}$ izražanju čustev, saj te odražajo notranjepsihično in medosebno čustveno regulacijo, ki je osrednji element medosebnih interakcij v odnosih navezanosti in čedalje pogostejši in pomembnejši predmet raziskav (Greenberg, 2008; Whelton, 2004).

\section{Kodiranje čustvenih izrazov}

Dosedanji zelo pester razvoj kodirnih sistemov je pokazal, da se je zelo težko približati idealnemu cilju takega sistema, namreč, izdelavi kod, ki bi se opirale na povsem eksplicitne kriterije, bile povsem kvalitativno razločene druga od druge in bi upoštevale različne pragove intenzivnosti pri vsakem čustvu. Običajno raziskovalci uporabljajo za izhodišče en kodirni sistem in ga nato priredijo svojim potrebam, pri čemer se največkrat oprejo na intuitivno presojo nekvalificiranih opazovalcev (npr. Butler idr., 2003, Whelton in Greenberg, 2005). Ob tem ugotavljajo, da je afekt $v$ interakciji zelo težko točno opredeliti, saj je vsaka interakcija del širšega konteksta in procesa, katerega čustveni pomen se oblikuje šele postopoma. Sledenje preveč podrobnim čustvenim odlomkom pogosto zamegli proces oz. celoto, iz katere je šele mogoče razbrati afektivno vzdušje posameznih drobcev (Cordova in Dorian, 1999). Iz tega razloga so številni raziskovalci razvili svoje globalne ali makrokode, ki združujejo v eni sami kategoriji (npr. napadalnost, ranljivost, branjenje) različne oblike vedenja in čustvovanja glede na to, ali te oblike v neki medosebni situaciji opravljajo enako funkcijo, k čemur je navadno dodana še stopnja intenzivnosti ter pogostost oz. trajanje (npr. Gee, Scott, Castellani in Cordova, 2002). Omenjeni težavi beleženja čustev se je mogoče delno izogniti tako, da upoštevamo, kako opazovane osebe same zaznavajo in poročajo o lastnih čustvih, čeprav tudi to ni vedno zanesljivo. Med drugim se je pokazalo, da je v parih, kjer so osebe čustveno intenzivno vpletene, zaznavanje oziroma poročanje o lastnih čustvih zaradi kognitivne obremenjenosti popačeno (Jacobson in Moorre, 1981; Floyd in Markman, 1983).

SPAFF (Specific Affect Coding System) je najpogosteje uporabljani in najbolj preverjeni mikrokodirni sistem druge generacije, kar pomeni, da na eni strani ohranja mikroanalitični pristop k opazovanju vedenja in čustvenih izrazov, kolikor poskuša konstruirane kode utemeljiti s podrobnim razčlenjevanjem obraznih izrazov, medtem ko na drugi strani vendarle kodira čustva ali afekte v ozadju vedenja in govorjenja in ne kodira posameznih gest, vedenja, izrazov ali stavkov (Gottman in Coan, 2007). Končni rezultat tega pristopa je, da nekatere kode opisujejo bolj čustva, npr. jeza, strah, gnus, prezir, pri katerih se lahko opremo na točno določene obrazne poteze, druga bolj vedenje, npr. napadalnost, zanimanje, pri katerih so izrazi obraza preveč raznoliki in nespecifični. Ker je bil sistem načrtovan za opazovanje razdiralnih konfliktov v parih, loči veliko negativnih kod, kot npr. jeza, kritika, prezir, prekinitev stika, napadalnost. Ena od posledic tega je, da koda jeza zajema zgolj jezo nizke intenzivnosti, medtem ko je močna jeza navadno kodirana kot napadalnost.

Sedanji kodirni sistem SPAFF (Gottman in Choen, 2007) se je razvil iz prvotnega, ki se je opiral na tri komponente, obrazno mimiko, ton glasu in telesno gibanje, povsem pa je izključil pomen izrečenega (CISS; Gottman, 1979). Ker se je pokazalo, da je stari sistem pogosto »prezrl gozd zaradi dreves «, bil pa je tudi preobsežen in počasen, je Gottman ponovno vpeljal besedni pomen, saj je ugotovil, da koderji spontano in tudi hitro ter točno povezujejo različne ravni opazovanja, pri čemer sledijo čustvenemu naboju povedanega, katerega nosilec je glas (Gottman idr., 1995). Sistem SPAFF v neobjavljeni verziji iz leta 1998 vsebuje 20 različnih kod, ki so opisane kot latentni psihološki konstrukti, kar pomeni, da se lahko neka koda (npr. zanimanje) pokaže prek različnih oblik vedenja in izražanja (strinjanje, povzemanje rečenega, prikimavanje in očesni stik). Koder pri ocenjevanju upošteva štiri ravni izražanja: besedni pomen, izraz na obrazu, gibanje telesa in ton glasu. Ena koda je v sistemu namenjena nevtralnemu vedenju, 13 je negativnih (jeza, napadalnost, prezir, branjenje, kritika, napetost/strah, gnus, nadvlada nizka in visoka stopnja, žalost, prekinitev stika, jamranje, humor iz zadrege) in 6 pozitivnih (naklonjenost, veselje ali navdušenje, humor, zanimanje, sprejemanje - nizka in visoka stopnja). Objavljena verzija iz leta 2007 (Gottman in Coan, 2007) vsebuje samo 18 kod: ne ločuje med obema nizkima oz. visokima stopnjama, humor iz zadrege porazdeli med humor in napetost/strah ter vključuje kodo grožnja, ki je »nadomestila« visoko stopnjo napadalnosti.

Prednost sistema je, da omogoča kodiranje dogajanja v dejanskem času, sliko za sliko, iz sekunde v sekundo, kakor se te odvijajo pred ocenjevalcem, ki za vnos kod uporablja posebno programsko opremo (James Long System). Program v sekundah beleži trajanje kode, ki se meri od vnosa ene kode do vnosa druge. Iz tega sledi, da lahko v vsakem trenutku eni osebi pripišemo samo eno kodo.

Primerjava kodirnega sistema SPAFF s sistemom BARS (Behavioral Affective Rating System) ter samoevalvacijskimi vprašalniki je pokazala, da sistem dovolj zanesljivo loči med različnimi oblikami vedenja in da se v grobem ujema s kategorijami v drugih sistemih prepoznavanja čustev $\mathrm{v}$ paru, čeprav ni znano, kakšna je zanesljivost posameznih kod (Johnson, 2002). Zaradi izključujočih se kod tudi ni mogoča faktorska analiza sistema. Faktorska analiza vzporednega sistema BARS je pokazala, da se čustva $\mathrm{v}$ partnerskih interakcijah lahko razvrstijo v štiri kategorije: jeza/prezir, veselje/ naklonjenost, žalost in tesnoba, kar med drugim upravičuje veliko število kod za negativni afekt v SPAFF sistemu. 


\section{Modificirani sistem SPAFF}

Pri sestavljanju navodil, usposabljanju in izdelavi novih kod smo se poleg navodil izvirnih avtorjev sistema opirali tudi na kodirni sistem, ki ga je na podlagi SPAFF priredila Janine Giese-Davis in njen laboratorij za kodiranje čustev na univerzi v Calgaryju (Giese-Davis, Piemme, Dillon in Twirbutt, 2005). Naš modificirani sistem, za katerega smo pridobili soglasje avtorjev iz Seattla (ZDA), je sestavljen iz 19 kod. Nevtralni afekt ima tako kot SPAFF eno samo kodo. Pozitivni afekt ima pet (5) kod: zanimanje, sprejemanje, naklonjenost/skrb, veselje/humor in ranljivost, pri čemer nismo ločevali med dvema ravnema naklonjenosti (z dotikanjem in brez), kot ločuje Giese-Davisova, pač pa smo zaradi redke uporabe združili kodi za veselje (ali navdušenje) in humor in po zgledu Heymana (Rapid Marital Interaction Coding System - RMICS, Heyman in Vivian, 2000) in Cordove (Intimacy Coding System, Dorian in Cordova, 1999) vključili kodo za ranljivost. Negativni afekt ima trinajst kod (13): napetost, strah, žalost, odprta jeza, zadržana jeza, prezir, nadvlada, napadalnost, branjenje, jamranje, gnus, sram in prekinitev stika. Tudi tu smo opustili ločevanje verbalne in neverbalizirane ravni strahu, žalosti in prezira iz priredbe Giese-Davisove, vpeljali kodo za sram in razdružili kodo za strah in napetost, ki sta $\mathrm{v}$ SPAFF združena.

S priredbo smo v sistem SPAFF tako vpeljali dve novi kodi, sram ter ranljivost, izpustili kodo za kritiziranje, združili kodi za veselje/navdušenje in humor ter razdružili samostojno kodo za napetost/strah v dve kodi ${ }^{1}$. Kodo kritiziranje smo izpustili, ker je bila vključena $\mathrm{v}$ sistem SPAFF zaradi specifičnihciljev raziskovanja priGottmanu, namreč ugotavljanje, kaj je najbolj pogubno vedenje $\mathrm{v}$ dinamiki para (Gottman, Coan, Carrere in Swanson,1998). Pokrivata jo kodi za jezo ali napadalnost. Glede sramu in ranljivosti terapevtske študije in modeli ugotavljajo, da sta sposobnost zaznavanja in toleriranja sramu ter izražanje ranljivosti ključna elementa pri ustvarjanju večje medosebne varnosti, zaupanja in intimnosti (Cordova in Dorian, 2004; Johnson in Greenman, 2006). Pomembnost

\footnotetext{
${ }^{1}$ Večletno spremljanje čustvenih izrazov med usposabljanjem bodočih terapevtov je pokazalo, da so spremembe v stopnji strahu in napetosti ter zaznavanje obeh občutij pomemben pokazatelj napredovanja terapevtskega procesa. Na začetku terapij običajno prevladuje vzdušje tesnobe, napetosti in zadrege, ki se šele kasneje izkristalizira $\mathrm{v}$ določeno čustvo, na primer strah, jezo ali sram. Ta proces postopnega zaznavanja in prepoznavanja čustev ima svojo razlago $v$ nevrofiziološki dinamiki tesnobe, pri kateri pretirano delovanje frontalnih, kognitivnih režnjev preprečuje povratni stik med limbičnim strukturami možganov ter frontalnimi režnji, s čimer onemogoča prepoznavanje in regulacijo čustev. Šele vzpostavitev te povratne zanke s pomočjo medosebnega reguliranja strahu na primer v terapiji omogoča jasnejše zaznavanje in prepoznavanje lastnih čustev. Taka dinamika po našem mnenju tudi pojasnjuje, zakaj pri kodiranju pogosto naletimo na oblike vedenja, ki imajo nejasno čustveno ozadje.
}

toleriranja sramu je nakazala tudi naša pilotska študija, v kateri smo pare spraševali po tem, kako so se spoznali (Rožič, Torkar, Erzar in Kompan Erzar, 2010). Kodi za veselje in humor sta združeni z pragmatičnega razloga: v terapiji konfliktih parov se redko uporabljata.

$\mathrm{V}$ nadaljevanju predstavljamo tabelo in opise posameznih kod, pri čemer smo skušali na kratko zajeti bistvene značilnosti kode, kakor se kažejo na štirih dimenzijah ocenjevanja (neverbalni izrazi na obrazu, drugi telesni izrazi oziroma gibanje, vsebina izgovorjenega in ton glasu). Bolj sistematični prikaz kod je predstavljen $\mathrm{v}$ dveh prosto dostopnih virih avtorjev Gottman in Coan (2007) ter J. Giese-Davis s sodelavci (2005).

\section{Nevtralni afekt}

Se kodira takrat, kadar ni izraženega nobenega afekta ali kadar je izraženo čustvo pod pragom kodiranja. Kadar je čustvo zgolj ubesedeno in ga spremlja nevtralni afekt, kodiramo nevtralno. To kodo potrjuje sama nečustvena vsebina povedanega in odsotnost fizičnih znakov čustvovanja. Kodiranje poskuša prestreči čustvene izraze tu in zdaj, zato je pomembno, ali je čustveni izraz dejansko prisoten $v$ sedanjosti ali pa je prisoten zgolj v besedah, ne pa tudi v izrazu, kot pri poročanju o preteklih dogodkih, kjer oseba o njih zdaj samo poroča ali jih objektivno presoja. O čustvih ne ugibamo, zato presojanja, kaj oseba v tistem trenutku dejansko čuti ali kaj bo oseba dejansko rekla o svojih čustvih $v$ tistem trenutku ali kasneje, ne smemo enačiti s kodiranjem čustvenega izraza. Pri kodiranju se držimo tega, kar vidimo in kar lahko zanesljivo rečemo o posameznem čustvenem izrazu. (To navodilo je malce drugačno od tega, kar velja za terapevtovo delo: to je bistveno bolj drzno, ko gre za ubesedenje čustev, saj se zanaša na čustveno povezanost $\mathrm{s}$ klienti $\mathrm{v}$ dejanski situaciji.). Primeri:

Klient govori o tem, da je jokal, a ne izraža nobenega afekta.

Klient sprašuje, ker je preslišal pomembno informacijo: "Kdaj se potem dobimo naslednjič? " (nevtralna vsebina, nevtralna energija)

\section{Zanimanje}

Zanimanje je odgovarjanje sogovorniku s pozitivno energijo, aktivna radovednost. (Terapevt išče stik na miselni ravni.) Oseba, za katero se zanimamo, je lahko partner, otrok ali klient. Lahko končujemo njegove stavke, pozitivno komentiramo povedano, ali ga prosimo za več informacij. Zanimanje mora imeti pozitivno energijo ali čustveno vsebino. Če je afekt nevtralen, kodiramo nevtralno. Zanimanje ni nujno $\mathrm{v}$ obliki spraševanja ali vprašanj. Kadar gre za spraševanje, se stavek zaključi s tonom navzgor in pričakovanjem odgovora, ki se kaže kot premor in molk spraševalca. Kar pomeni, res ga zanima in želi slišati odgovor. Retorična vprašanja ali vprašanja izrečena zaradi preusmeritve pozornosti, zadrege ali 
Tabela 1. Seznam kods kraticami in kratkimi pojasnili

\begin{tabular}{lll}
\hline Koda & Kratica \\
\hline 1. & Nevtralni afekt (ali afekti, ki ne dosegajo praga) & NEV \\
2. & Zanimanje (z malo afekta, kognitivno, prikimavanje) & ZA \\
3. & Sprejemanje/Ovrednotenje (terapevt sprejema, pojasnjuje) & SP \\
4. & Naklonjenost (terapevt aktivno poseže v odnos, nudi oporo) & NAKL \\
5. & Veselje, humor & V \\
6. & Napetost (zadrega zaradi trenutne situacije, brez očitnega sramu) & NA \\
7. & Strah (izraženi in/ali telesni) & ST \\
8. & Žalost (z jokom, solzami in/ali brez) & Z \\
9. & Frustracija/Zadržana jeza (tudi nemoč, kadar gre v smeri jeze) & FRU \\
10. & Odkrita jeza & $\mathrm{J}$ \\
11. & Zaničevanje/Prezir (nakazan in/ali izrečen) & ZN \\
12. & Nadvlada (v drži in/ali besedah) & NDV \\
13. Napadalnost (v drži in/ali besedah) & NPD \\
14. & Branjenje (v drži in/ali besedah) & BRA \\
15. Jamranje/Pritoževanje (nemoč brez jeze) & JAM \\
16. & Gnus & $\mathrm{G}$ \\
17. & Sram (zadrega, ki meji na sram in presega trenutno socialno situacijo) & SR \\
18. & Prekinitev stika & PS \\
19. & Ranljivost (izražanje ranljivosti) & $\mathrm{R}$ \\
\hline
\end{tabular}

jeze, niso zanimanje. Zanimanje se lahko pokaže tudi prek besed, kot so npr. »me zanima«, »zanimivo«, »nenavadno«, »povejte kaj več«. Glas je staccato (zaletav, pretrgan) $\mathrm{s}$ pozitivno energijo in visokim tonom. Tudi blago navdušenje kodiramo kot zanimanje. Zanimanje je kodirano tudi takrat, a redko, kadar se nekdo zanima za svoja notranja stanja. Čelo je nagubano, lici dvignjeni, ustnice razpotegnjene, telo nagnjeno naprej. Primeri:

Terapevt: "Kako ste se počutili, ko ste ji povedali, da jo imate radi?»

Terapevt: "Kako vam je bilo, ko ste se peljali domov po tem srečanju?«

Klient: »Bi mi lahko povedali, kako se tega lotim?«

Udeleženec: »In koliko ste stari?« (Vprašanje drugemu udeležencu, ki je omenil, da ima rojstni dan. Pozitivna energija.)

Udeleženec: »Je rekla, naj še pridete? «(Vprašanje drugemu udeležencu, ki je obiskal bolno osebo.)

Terapevt: »Bi lahko kdo po skupini izpolnil vprašalnik? « (Se ozira po skupini, ni preveč napet in išče očesni kontakt)

Klient: "Ali obstajajo kake metode za zmanjševanje jeze?" (Vprašanje terapevtu, zanimanje in iskanje pomoči.)

Klient: »Me pa res zanima, kdo se komu prilagaja?" (Vprašanje ženi, ki ni izraz zanimanja, ampakjeze. Ironično vprašanje.)

\section{Sprejemanje}

Sprejemanje ali ovrednotenje je odprtost za probleme drugega, sprejemanje njegovih besed in čustvenega stanja, zrcaljenje povedanega ali čustvenih stanj sogovornika, izražanje ali izžarevanje spoštovanja. (Terapevt sprejema vase, kar sogovornik izžareva ali skuša ubesediti.) Sprejemanje pomeni odprtost in spoštovanje. Odprtost se nanaša na stališča sogovornika, tudi če se z njimi ne strinjamo. S sprejemanjem sporočamo razumevanje in podporo, tako da povzamemo povedano. Tudi če sprejemanje izražamo $\mathrm{v}$ nevtralnem tonu, ne gre le za izmenjavo informacij.

Kadar je $v$ glasu empatija in toplina, na obrazu pa zrcaljenje, kodiramo naklonjenost. Za kodo sprejemanje mora biti povzemanje povedanega točno. Pozitivne pripombe ali komentarji so del vsakdanjih pogovorov tudi izven terapij ali skupin (npr. med sodelavci, športniki, študenti, v družini). Sprejemanje se lahko nanaša na lastne izkušnje in doživljanje opore (npr. nekdo pove, da ga je romanje globoko ganilo; nekdo reče, da je iz določene knjige zvedel veliko dragocenega), kar pomeni, da doživlja ali podoživlja sprejemanje. Vedenje: prikimavanje in očesni stik, glasovi, ki kažejo na strinjanje in odobravanje. Čelo je nagubano, lici rahlo dvignjeni, kotički ust zategnjeni nazaj. Primeri:

Terapevt $z$ malo energije posluša klienta (odzvanja povedano in povzema čustveno vzdušje povedanega): »Rekli ste, da je bila hiša prazna, temna, najbrž vam ni bilo lahko.»

Terapevt: "To se sliši zelo ugodno." (potrditev)

Terapevt: "Lahko bi se še bolj sprostili.» (komentira, potrjuje)

Terapevt: »Ko poslušam, kaj pravite, si mislim, da je bilo najbolj ganljivo, ko ste ji rekli, da je morda ne boste več videli« (povzema in izraža svoje mnenje)

Udeleženec: "To je bilo res nekaj posebnega.» (pohvala, nevtralni ton glasu) 


\section{Naklonjenost}

Naklonjenost ali skrb (ang. affection/caring) vključuje izžarevanje topline, empatije, sočutja, solidarnosti in se kaže kot zbližanje ali iskanje stika z namenom nudenja tolažbe in opore. (Terapevt vzpostavi čustveno povezanost.) Verbalno se kaže prek spodbujanja, pohvale ali izražanja podpore, ali kot zaskrbljeno spraševanje ali pogovor z naklonjenim tonom. Obrazna mimika in topel ton glasu mora ustrezati verbalnemu izrazu. Vedenje: na obrazu se kaže skrb, ali pa obraz zrcali čustva sogovornika ali skupine sogovornikov. Naklonjena oseba se navadno nagne naprej, ali nagne glavo na stran in/ali nazaj. Ton glasu je nizek, legato (gladek in povezan brez prekinitev), ali pa afektivno posnema glas osebe, ki ji odgovarja. Koda nima posebnih obraznih potez. Primeri:

Terapevt (s sočutjem): »Vi pričakujete, da vas bodo oni prav tako radi povabili zraven, kot bi vi njih." Klient: »Rad bi se vam zahvalil, ker ste me poklicali. Zelo mi je pomagalo ... » (topel ton glasu, bližina, ki postane visoka, ko se par prime za roke) Udeleženka: „To je bil res dober obisk." (topel ton glasu)

Udeleženec opisuje, kako sta se z bolnico prijela za roke (toplina, bližina)

Udeleženka se zahvali drugi udeleženki za obisk (toplina, bližina)

\section{Veselje in humor}

Veselje je tudi sproščenost, radost, navdušenje. Ta koda označuje visoko stopnjo pozitivne energije. Gre za govorjenje s hitrimi nihanji v višini, hitrosti in jakosti ter pretiranimi poudarki na posameznih besedah. Če bi tem besedam lahko na koncu dodali klicaj ali če je vsebina pozitivna, potem gre za kodo veselje. Ta koda se razlikuje od zanimanja po stopnji intenzivnosti in po navdušenju. Ta koda pride pogosto v poštev, kadar se ljudje pozdravljajo, srečujejo, pa tudi med pripovedovanjem doživljajev. Sem spada tudi prijetno presenečenje. V terapiji se uporablja redko. Primeri:

\section{Udeleženka: »Vstopim in rečem: Glej jo!!" (visoka stopnja pozitivne energije) \\ Udeleženec: „Še nikoli nisem videl česa takega!« (visoka stopnja pozitivne energije) \\ Udeleženka: "Bilo je čudovito!" (opisuje kraj, kamor je odšla na izlet, visoka stopnja pozitivne energije)}

Izražanje dobre volje prek šal, pripoved o smešnih plateh dogodkov, dobronamerno karikiranje. Kodiramo ga z isto kodo kot veselje. Načeloma se loči od veselja po tem, da sta v humor vključeni najmanj dve osebi. Čustveni ton $\mathrm{v}$ ozadju je sreča in pristni občutek, da je nekaj smešno. Humorja ne smemo mešati z napetim humorjem, ki je izraz napetosti. Tudi stavek, ki sproži smeh, čeprav ni bil izrečen kot tradicionalna šala, kodiramo kot začetek humorja. Izraz obraza je pri obeh kodah podoben: nagubano čelo, dvignjene zgornje ustnice in lici, odprta, razpotegnjena usta. Glas je višji in močnejši. Primeri:

Udeleženec: »Saj bo razumela, ko bo vzela tableto
(pove šaljivo opazko o starejši osebi, ki se opazki
smeji, skupaj z govorcem, opazka je naklonjena)
Udeleženka: »No, če želijo nekaj res zanimivega
...« (Nadaljuje s tem, kaj bi lahko predstavila na
televiziji med svojim intervjujem, se hkrati ozira po
skupini ter izžareva dobro voljo in hudomušnost)
Udeleženka: »Kaj, da bi pustila možu, da to
naredi?! Ta je pa dobra! (humor se preveša v
posmeh, zato kodiramo veselje in prezir)

\section{Napetost}

Napetost se pogosto pojavi tedaj, ko se v pogovoru pojavi neprijetna tema. Napeti govorec bo $\mathrm{s}$ težavo izrazil tisto, kar hoče povedati. Pogosto začne izgovarjati nepopolne ali nedokončane misli ali pogosto izgovarja 'uh' in 'ah', ne da bi povedal, kaj misli (to ni isto kot iskanje primernih besed ali ustavljanje ob sestavljanju misli). Govorec je lahko zelo napet ali si grize ustnice. Napetost se pogosto kaže kot neke vrste trenje znotraj govorca. Kot bi delal kakšno izometrično vajo, bo govorec fizično pritiskal nase oz. se stiskal - ali s stiskanjem ustnic ali stiskanjem rok, ali pritiskanjem rok na kakšen drug del telesa (drgnjenje obraza,...), mečkanjem ustnic ali kakšno drugo nesproščeno poteza ali glasom. Jecljanje ali uporaba kakšnega drugačnega verbalnega mašila (uh, um, e ...) je vrsta vokalnega pritiska in se kodira kot napetost. Vokalna/verbalna napetost se kodira, ko govornik uporabi trikratno jecljanje ali mašilo. Ob poslušanju napetega govorca postane napet tudi poslušalec oz. tisti, ki kodira. Pod napetost spada tudi zadrega.

Fizični znaki: nasmešek brez občutka, pogosti premiki oči, dvignjene obrvi, grizenje ustnic, nemir. Nemir vključuje tudi dotikanje obraza, križanje nog in gubanje čela.

Primeri: kadar nekdo na terapiji dolgo govori ali mora začeti z govorjenjem, kadar pove nekaj kritičnega, kadar ga je strah, pa tega strahu še ni čutiti.

\section{Strah}

Strah je čustvo, ki je redko izraženo odprto. Ženske v skupini obolelih za rakom so izražale strah v povezavi z njihovo boleznijo, ali pa skupaj z odzivom, ki so ga dale na težko temo, o kateri se govori v skupini. Potrebno je biti pazljiv, da se strah ne pomeša $z$ napetostjo. Strah je veliko bolj intenziven in manj pogost kot napetost, ki je opisana zgoraj. Beseda zaskrbljen bolj pogosto kaže na skrb ali preveliko obremenjenost $\mathrm{z}$ nečim, kot pa na strah in jo zato redko kodiramo kot strah. J. Giese-Davis in sodelavci (2005) ločijo dve stopnji strahu: verbaliziran strah in visoko raven strahu: 
1. verbaliziran strah: kadar nekdo govori o tem, da ga je nečesa strah, ni pa fizičnih znakov strahu; verbalizirani strah mora biti izražen $\mathrm{z}$ besedami, ki res kažejo na strah (npr. prestrašen, ustrahovan, boječ, v krču, prikovan).

2. visoka stopnja strahu: kadar nekdo izgleda, kot bi bil v neposredni nevarnosti (kot srna, ko jo obsvetijo žarometi). Tak človek s fizičnimi znaki pokaže svoj strah, vendar pa ga kljub temu morda ne verbalizira.)

Vedenje: pogosti premiki oči, široko odprte oči, nemir, nagubano čelo, hitro dihanje, zamrznjena drža telesa.

\section{8. Žalost}

Žalost se izraža na več načinov. V nekaterih primerih lahko posameznik reagira resignirano in nemočno, kot bi bil popolnoma brez energije. $\mathrm{V}$ drugih primerih pa je lahko posameznik poln energije in hkrati izraža žalovanje ter izgubo. Kot žalost kodiramo tudi obup, nemoč (ki je brez jeze), vdanost, potrtost, strtost, čustveno bolečino, prizadetost. (V sistemu J. Giese-Davis in sodelavcev (2005) obstajata dve stopnji žalosti: vsa žalost, ki ni na visoki stopnji, je kodirana kot žalost nizke stopnje; visoka stopnja pomeni močno žalost, ki je pospremljena s solzami, ali ko glas govorca zveni, kot bi ta jokal. Visoka stopnja žalosti je kodirana tudi tedaj, ko je posameznik preveč preplavljen z občutji, da bi lahko govoril.)

Izraz na obrazu: žalostne oči (pogosto pogled navzdol), povešeni kotički ust ali navzdol ukrivljene ustnice (pri joku). Glas je nižji ali se trese, vzdihi so dolgi in brez energije. Ko oseba prehaja $\mathrm{v}$ žalost ali se prebuja iz žalosti, ti znaki pogosto delujejo skupaj: povešene oči gredo skupaj z nižjim tonom. Bolj pogosto kot ne se hkrati $\mathrm{z}$ dvignjenim pogledom dvigne tudi energija $\mathrm{v}$ glasu ter govorca premakne ven iz žalosti.

Vsebina pripovedi izraža žalost, izgubo. Potrebno je biti gotov glede tega, da se govorec nanaša na sedanji ali trajajoči občutek in ne na žalostna čustva iz preteklosti. Če nekdo v skupini ne govori veliko, je to morda zato, ker je za njim težak teden, in se opravičuje s tem, da je bolj na tleh ali melanholičen. Ljudje, ki so žalostni, navadno manj govorijo, ne dajejo veliko podatkov ali informacij, zelo na kratko povedo stvari in npr. preprosto rečejo, da je bilo hudo.

Primeri: udeleženec joka; poroča o smrti nekoga; joka, ker je zbolel mož.

Klientka: "Žalostna sem in hkrati mi je bolje, ker vem, da ne trpi več."

Udeleženka: »Žalostna in nezadovoljna sem zaradi svojega dela.«

Klientka: „Čutim, da mi življenje uhaja iz rok» (obupano).

Udeleženka: »Mislim, da je bilo tvoji materi zelo hudo« (ima solzne oči).

\section{Frustracija/Zadržana jeza}

Ko nekdo izraža frustracijo, zveni tako, kot bi bil razdražen, nejevoljen, naveličan, besen ali na robu potrpljenja. Frustracija je pogosto označena z notranjim konfliktom, ki še ni razrešen, zato je po tej plati podobna nemoči ali napetosti, ker notranja jeza še nima pravega izraza. Videti je lahko kot nerazrešen notranji konflikt ali kot mešanica jeze in napetosti, kot da je oseba vznemirjena in ne more iti preko te točke. Frustracijsko zadržana jeza se razlikuje od napetosti - namesto stalnega nemira se kaže v majhnih izbruhih, ki se končajo na hitro. Kot bi v glasbi slišali t.i. staccato, določene besede se posebej poudari. Gre za kombinacijo napetosti in izrazitosti (kot bi govorili skozi stisnjene zobe).

Vedenje: napetost okrog ustnic, stiskanje ustnic skupaj. Včasih se zdi, da se potlačena frustracija kaže skozi nasmešek brez občutka. Včasih govorca izda rahlo trzanje z glavo med govorjenjem. Včasih pride do pojecljavanja, sprememb v ritmu govora ali poudarkih, ki se jih da posameznim besedam. Spremljati je treba tudi premike prsnega koša.

Med govorom se izraža iracionalni nemir, ogorčenost, kot bi govorec kapituliral. Fraza, ki pogosto označuje frustracijo/zadržano jezo je 'Argggh!' ali 'Joooj!' Ljudje, ki so frustrirani, pogosto veliko govorijo, ta govor pa je napet, odločen, prsni koš se premika ostro, pri govoru je slišati poudarjanje posameznih besed. Primeri:
Klient: »Ugotovil sem, da imam kar nekaj jeze v sebi.«
Udeleženec: "Tako sem že naveličan te svoje bolezni« (z rokami oz. dlanmi udari po naslonjalu za roke na stolu).
Udeleženka: "Po svoje je neumno, da bom zdaj dva tedna hodila tja.«

\section{Odkrita jeza}

$\mathrm{V}$ primerjavi z drugimi čustvi je jeza direktna in jasna. Gre za odločnost oz. namenskost, kot bi bilo z izražanjem jeze nekaj doseženo. Jezni govorec lahko graja ali obtožuje nekoga drugega in morda zvenijo njegove besede neracionalno. Besede so take, kot bi želel z njimi udariti in odrezati. Jeza je pogosto občutena kot eksplozija ali olajšanje (v nasprotju s frustracijo, ki je zadržana).

Vedenje: dvignjene obrvi in zgornja ustnica, stiskanje ustnic, nehoteno trzanje ali nenamerni sunki, skupaj stisnjene čeljusti in zobje. Mišice na vratu in čeljustih so napete. Ton glasu naraste ali pa se zniža glede na običajen obseg; spremeni se tudi način, kako so poudarjene besede. Direktna jeza nima drugega namena, kot da se izrazi. Če gre za veliko več besed, potem gre najbrž za zadržano jezo. Direktna jeza je slišati zelo na kratko in jasno. Primeri:

Udeleženka: udarja s pestjo ene roke v dlan druge, medtem ko govori o napredovanju svoje bolezni. Udeleženka: "Prav nič na tem prekletem svetu ni 
nujno, razen umreti. Kako bi ga udarila!« Govori o zdravniku, ki ji je rekel, da se bo njen rak nujno spet pojavil.

Klientka: "To bi vi morali vedeti, saj ste terapevt. Poslušajte me, no.« (Glas povišan, oseba glede terapevta, nato zmajuje $z$ glavo, kot znak neodobravanja, in spet pogleda terapevta)

\section{Zaničevanje/Prezir}

Prezir kaže na povsem jasno pomanjkanje spoštovanja do nekoga ali nečesa. Je precej drugačen od golega nestrinjanja in precej bolj uničevalen od odprte jeze. (J. Giese-Davis in sodelavci (2005) ločijo dva tipa prezira: t.i. mikromomentni prezir, pri katerem opazimo samo fizične znake prezira, in verbalizirani prezir, kjer gre za ubeseden prezir s fizičnimi znaki ali brez njih. Ta tip prezira nakazuje nadvlado, hlad, poniževanje.) Zaničevanje in prezir prepoznamo po sarkazmu, sovražnem humorju, zasmehovanju, uporabi žaljivih imen ali pridevkov in odkritem žaljenju. To kodo se najpogosteje uporabi tudi takrat, kadar govorec poroča o tem, kar je storil nekdo drug, pri čemer se sam s tem ne strinja ali ga to jezi; takrat navadno zaničljivo posnema vedenje in besede te osebe. Prezir lahko nekdo izraža tudi do sebe. Izraz na obrazu je tipičen: zakrivljene ustnice na eni strani ust ali obeh, zavijanje z očmi. Primeri:

Udeleženec: »To je pa res zoprno.« (govori o tem, da se nekdo joka brez razloga)

Klient: se posmehuje obiskovalcem, ki so pri bolničini postelji šepetali med seboj (na obrazu naredi izraz 'Mislim, $k$ 'r neki')

Udeleženka: pripoveduje skupini o tem, kaj jo je spraševal novinar, in pri tem zavija z očmi.

$V$ tekstu prepoznamo sovražen humor, žaljivke. Odzive na sarkazem, ki so tudi navidez sarkastični, razumemo kot zrcaljenje in jih zato kodiramo kot nizko naklonjenost.

\section{Nadvlada}

Cilj takega vedenja je nadvladati drugega ali druge. Nekdo, ki nadvladuje, poskuša prisiliti drugega $\mathrm{k}$ poslušnosti ali $\mathrm{k}$ temu, da se ta umakne ali pristane na njegov »prav«. Nadvladovanje pogosto vključuje pokroviteljski ton, razvrednotenje mnenja drugega in dajanje lekcij (»pridiganje «). Oseba, ki nadvladuje, pogosto navaja avtoritete ali uporablja klišeje ter puhle fraze, da bi podprla svoje stališče. Taka oseba bo vztrajala na tem, da je glavna in bo prekinjala druge ali govorila preko njih. Sem spada tudi hvaljenje, katerega namen je sporočiti drugemu, da je govorec boljši od njega. Pri nadvladovanju sta prisotni najmanj dve od treh lastnosti: ton glasu, vsebina in fizični znaki.

Vedenje: brada se pomakne navzdol, telo se nagne naprej, mahanje s kazalcem, glava je nagnjena na eno stran, obraz je mračen, mrk. Obrvi se na obeh straneh dvignejo. Govor teče neprekinjeno s poudarki, ritmom in pokroviteljskim tonom (kot bi nekdo ravnal s tabo kot $\mathrm{z}$ majhnim otrokom). $\mathrm{V}$ tekstu prepoznamo nadvlado kot pridiganje, dajanje lekcij, pokroviteljstvo. Primeri:

Udeleženec (v predavateljskem tonu govori
skupini): »No, to imam jaz od vas..."
Klientka: »Nikakor me ne bo nihče učil, kako in
kaj.« (nepopustljivo in močno)
Terapevt (klientom ob začetku srečanja poroča o
svojem obisku ZDA): »Tudi mi terapevti se moramo
stalno izobraževati«. (daje vedeti, da je pameten in
sposoben)

\section{Napadalnost}

Napadalna oseba deluje tako, da izzove odziv, kot bi hotela začeti spopad ali izzivanje drugega. Za napadalnostjo se skriva namera, da od nekoga $\mathrm{s}$ pritiskom na njegove šibke točke izzovemo reakcijo Po tem se razlikuje od nadvladovanja, katerega namen je uničiti mnenje drugega in iz njega izsiliti priznanje. Pri napadalnosti gre za posmehljiva vprašanja, vprašanja, na katera je nemogoče odgovoriti, ne da bi sebe postavili $\mathrm{v}$ nevzdržen položaj. Gre za izzivalne stavke, s katerimi se provocira drugega. $\mathrm{V}$ vsebini povedanega prepoznamo porogljiva vprašanja, izzivanja, provokacije.

Fizični znaki: čeljust je potisnjena naprej, glava potegnjena nazaj, osrednji del čela naguban, včasih tudi stranski. Pogosto bo govorec potisnil glavo naprej in jo nato potisnil nazaj (z njo zamahoval). Ton glasu je lahko ritmičen in se lahko dvigne ob koncu stavka. Primeri:

Udeleženka: »Zakaj ne greš $k$ zdravniku?« (izziv sogovorniku, ki ima znake bolezni, a o njih še ni govoril z zdravnikom)

Udeleženka: »Ampak saj si morala govoriti o tem s svojimi otroci« (namiguje, da je njena sogovornica gotovo morala otrokom reči tudi kaj o napredovanju svoje bolezni)

Klientka: »A res tako mislite?" (izzivanje terapevtke glede njenega mnenja o samomoru)

Klientka: »In kaj je cilj teh skupin?« (napad na terapevtko in njeno vodenje skupine)

\section{Branjenje}

Branjenje ali obrambna drža sporoča navidezno nedolžnost, kot bi človek hotel reči: ' Pusti me pri miru. Kaj se spravljaš name?' Pri kodiranju bomo pozorni na 'Ja, ampak... ' stavke, izgovore, pritoževanja čez druge in kritiziranje, katerih namen je odvračanje kritike, ki je bila prvotno namenjena govorcu. Pred sabo imamo človeka, ki dvigne roke pred obraz, kot bi se hotel ubraniti pred napadom. Zavedati se je potrebno, da pogosto ni jasno, kaj govorec sploh vidi kot grožnjo; morda lahko brani celo koga drugega in ne sebe.

Branjenje je običajno direktno povezano z določenim posameznikom oz. njegovimi izjavami, pred katerimi se nekdo brani, in se kaže skozi vsebino obrambnega stavka, 
kot je npr. 'No, tega pa nisem vedel' ali ‘Tega mi ni nikoli povedala', ali skozi fraze, katerih del je vprašanje, kot npr. 'In kako naj bi mi to vedeli?'. V vsebini povedanega prepoznamo pritoževanje, kritiziranje. Veliko obrambnih verbalnih reakcij se začne $\mathrm{z}$ »Jaz-stavki« ali vsebuje besedico »saj« ali imajo obliko vprašanja, ki se začne »Kako naj bi jaz...?«.

Vedenje: Roke so prekrižane čez prsi in možen je prisiljen nasmeh, čelo nagubano, obrvi dvignjene. Ton glasu je nihajoč ter višji. Primeri:

\begin{abstract}
Klient se brani, ker nima ničesar, kar bi lahko povedal.

Udeleženka pove drugi udeleženki, da se jo boji še bolj prizadeti.

Terapevtka previdno pojasni, da bi bila lahko ta žalost v zvezi z nečim, česar sama še ne pozna.

Klientka odgovarja na možev jezni komentar, kako je mogoče, da v njeni družini sicer govorijo o povezanosti, a njih nikdar ne povabijo na praznovanja: »Saj bi nas povabili, ampak... » (ne nadaljuje in pogleda terapevta).
\end{abstract}

\section{Jamranje/Pritoževanje}

Jamranje oz. pritoževanje je kodirano tedaj, ko jamrajoč ton glasu ne spada $\mathrm{v}$ vsebino, ki bi kazala na drugačno kodo, navadno obrambnost. Vsebina pri jamranju oz. pritoževanju je čustveno nevtralna, v smislu trivialnega pritoževanja nad vremenom.

Vedenje: glas je jokajoč, kot bi pel z višjim glasom, kot je običajno. Čelo je nagubano, kotički ust so povešeni oz. upognjeni navzdol.

Verbalizacija: Trivialne pritožbe. Pogosto glede logistike ali tehničnih težav, kar izdaja rahlo zadrego ali iskanje stika. Pogoste so pritožbe čez vreme.

\section{Gnus}

Gnus je nehotena reakcija na škodljiv dražljaj. Predstavlja fizični odpor na nekaj in aktivno zavrnitev nečesa, kar je za posameznika odbijajoče. Dražljaj, ki sproži gnus, je lahko neprijetno ravnanje, napredujoča bolezen ali specifično vedenje določenega člana skupine, zdravnika ali koga drugega. Reakcija je nehotena, kakor da človek ne more zaustaviti dvigovanja želodca ali tega, da mu gre na bruhanje. To je redka koda, ker je izjemno močna in je bolj fizična kot čustvena. Včasih jo lahko vidimo pri osebah, ki so zaradi zdravljenja postale posebno občutljive na vonj. Te kode ne smemo zamešati s prezirom.

Verbalizacija: komentarji, kot so »bljak«, »bbb«, »ae«. Obrazni znaki so značilni in očitni: vihanje nosu, dvigovanje zgornje ustnice in lic, spuščene obrvi, včasih tudi obračanje glave vstran.

Primer: Klientka govori o svojem telesu in občutkih, ki jih v njej prebuja pogled na njeno telo.

\section{Prekinitev stika}

Prekinitev stika (ang. stonewalling) vključuje popolno prenehanje poslušanja in aktivno izključitev iz pogovora. Vedenje ob prekinitvi stika vključuje obračanje vstran, npr. pogled stran, ukvarjanje samo s samim seboj (automanipulation), kar s seboj nosi sporočilo 'Zdaj raje ne bi bil tukaj'.

Vedenje: negiben, navidez brezizrazen ali zamrznjen obraz, s stisnjenimi čeljustmi, vrat trd.

\section{Sram}

Sram je močno, vase usmerjeno občutje: oseba doživlja, da je z njo v temelju nekaj narobe. Pogosto je povezan z občutki krivde zaradi dejanj, ki so za posameznika nemoralna oz. neprimerna. Za občutje sramu je značilna upočasnjena aktivnost: posameznik se ob tem, ko začuti sram, upočasni ali celo ustavi (npr. v pripovedovanju). $\mathrm{V}$ takih trenutkih je ranljiv, počuti se osamljenega, izpostavljenega, povsem nemočnega in obupanega. Občutju sramu se je mogoče tudi izogniti. Tedaj govorimo o izkrivljenem odzivu na sram ali izmikanju sramu, na primer prek besa, napada na druge, manipulativnega naslavljanja na sogovornika ali zanimanja zanj in drugih oblik preusmerjanja pozornosti: človek ne ve, kaj bi, je jezen, frustriran, razdražljiv, napadalen. Vse te izkrivljene izraze sramu kodiramo po očitnem vedenju in ne kot sram.

Motnje govora - prekine se govorni tok, človek se začne odkašljevati, ali spuščati glasove, kot so »gmmm《 ali »aaaa...mm«. Upočasni se tudi intenziteta govora, jakost tona pade.

Vedenje: nezmožnost ali prekinitev očesnega kontakta, rdečica na negibnem obrazu, ramena padejo, glava se povesi, posameznik se včasih potegne nazaj v stol.

Verbalizacija: tipični stavki ali besede, ki kažejo na to, da govorec doživlja sram: » To pa ne... Meni je tako nerodno. Sram me je. Bil sem v zadregi. Počutim se kot največji bedak. Nočem, da bi me kdo videl. Ne vem, kaj mi je bilo. Nelagodno mi je.«

\section{Ranljivost}

$\mathrm{S}$ to kodo označimo ravnanje osebe $\mathrm{v}$ medosebni situaciji, ko oseba razkrije šibke ali sramotne vidike sebe, ne da bi od tega imela kako korist, oziroma tedaj, ko tvega, da jo bo sogovornik kritično ocenjeval ali napadel. To lahko stori neposredno, tako da govori v prvi osebi o sebi in se ne brani ali opravičuje, ali posredno, tako da se skrije za pripoved o kaki sorodni stvari. Običajno se ton glasu zniža. Oseba lahko čuti sram, a kljub temu govori naprej in opiše svoje občutje osramočenosti in ne obtožuje nikogar. Sram, ki je izražen na ta način, kodiramo kot ranljivost. Ranljiva oseba je brez obramb in tvega odprto držo do sogovornika, saj ne ve, kako jo bo ta sprejel. Obrazne poteze so podobne tistim pri sramu in napetosti. 
Primer:

Udeleženec: »Vedno se počutim tako majhnega, kadar me žena ošteva in pravi, da je vse, kar rečem, čisto pretvarjanje. Takrat bi najraje odšel.»

\section{Postopek kodiranja}

Ker nismo imeli na voljo ustrezne programske opreme, ta je sicer podrobno predstavljena v članku avtorjev Kahng in Iwata (1998), smo se pri časovni delitvi sekvenc oprli na sistem BARS, kar pomeni, da smo posneto gradivo razdelili na polminutne odseke in dovolili uporabo več kod za posamezni odsek. Na ta način smo hoteli s kodami zabeležiti tudi tiste oblike vedenja, ki imajo nejasno čustveno ozadje, kot npr. napetost in tesnoba (Johnson, 2002). Gradivo za usposabljanje smo posneli s kamero (s sliko in zvokom), včasih samo zvočno, ker smo na podlagi dosedanjih izkušenj s snemanjem terapij domnevali, da zaradi zaupnosti ne bi dobili dovolj soglasij za snemanje slike in zvoka hkrati in da bi z video kamero preveč vplivali na občutek varnosti pri udeležencih terapij. Posnetke smo transkribirali in v besedilu označili meje med sekvencami. S programom Audacity smo zvočne posnetke razdelili na polminutne sekvence in jih označili s petsekundnim zvočnim signalom, ki ocenjevalca opozori na to, da se ena sekvenca končuje in se začenja druga.

Posamezni posnetek so si ocenjevalci ogledali ali poslušali dvakrat brez kodiranja in pri tem upoštevali pravila dobrega kodiranja. Po končanem ogledu so si v glavi zamislili možne kode in jih preverili s transkriptom. Nato so posnetek zavrteli še enkrat s premori in ga ob tem kodirali, pri čemer so kode sprva pisali na transkript ter jih nato vpisali v Excel tabelo. Četrti ogled ali poslušanje je bilo namenjeno preverjanju kod. Koderji so za vsako sekvenco uporabili za vsakega udeleženca, ki v sekvenci spregovori ali se kako drugače zvočno odzove, vsaj eno kodo (četudi je to koda nevtralno). Kadar so bili glede uporabe neke kode pri določeni osebi negotovi, so ta problem izpostavili po končanem kodiranju. Sledilo je skupno poslušanje posnetka in diskusija $\mathrm{v}$ timu, katere cilj je bil določiti ustrezno kodo za konkretno situacijo, interakcijo ali osebo. Določitev kode je sledila splošnim navodilom, v primeru nejasnosti ali premajhne intenzivnosti pa so ocenjevalci kodo določili s konsenzom. Ocenjevalci niso imeli vpogleda $\mathrm{v}$ celoten potek terapij in kadar so bili posnetki del kake raziskave, niso bili seznanjeni z raziskovalnimi vprašanji in hipotezami.

$\mathrm{Na}$ podlagi izkušenj $\mathrm{s}$ kodiranjem terapevtskih treningov smo se odločili, da lahko ocenjevalec za vsako sekvenco vpiše več kod, četudi ocenjuje samo eno osebo. $\mathrm{V}$ nekem trenutku je lahko na primer oseba napeta, hkrati malo jezna in pokroviteljska. Načeloma ocenjevalec kode razvrsti po jakosti: najprej kodira afekt, ki je najmočnejši, nato afekt, ki je po moči za njim in tako naprej. Vsako osebo kodira posebej (po potrebi lahko dodatno kodira tudi situacijo v celoti).

\section{Usposabljanje ocenjevalcev in pravila dobrega kodiranja}

Usposabljanje ocenjevalcev je potekalo enkrat tedensko v okviru doktorskega študija Zakonske in družinske terapije na Teološki fakulteti Univerze $\mathrm{v}$ Ljubljani. Udeležilo se ga je osem študentov in je trajalo dva meseca. Pokazalo se je, da je za visoko ujemanje med ocenjevalci in gladek potek kodiranja potrebno temeljito poznavanje kod in čim več izkušenj z različnimi posnetki.

V prvih korakih usposabljanja so se ocenjevalci držali naslednjih treh pravil dobrega kodiranja, ki smo jih povzeli po avtorjih Gottman in Coan (2007) in priredili za potrebe kodiranja terapij:

1. Opazuj vedenje, kot bi predstavljalo samo eno od številnih možnih reakcij v tisti situaciji. Ljudje bi lahko v napeti situaciji, na primer: a) rekli, da je napeto, b) ali da jih je strah, c) ali pa bi utihnili in obtičali v eni in isti telesni drži, č) začeli veliko govoriti in iskati oporo prek očesnega stika, d) postali nemirni, e) se začeli praskati, vrteti prste in prijemati dele telesa. Če njihovo reagiranje opazujemo kot izraz nečesa afektivnega v ozadju, lahko ugotovimo, da so ti izrazi vendarle izbire, čeprav jih ljudje običajno ne izberemo zavestno.

2. Afektivni pomen nekega izraza lahko ugotovimo tudi tako, da se vprašamo, kako se počuti oseba, ki tako ravna ali se tako vede. Ali pa, da se vprašamo, kako nam bo ta oseba sporočila, kako se počuti in kako ji je. Ali pa tudi, kaj nam želi o sebi sporočiti. Situacije, ki jih kodiramo, so vedno medosebne, zato lahko predpostavimo, da so tudi izrazi vedno vpeti $\mathrm{v}$ sporočanje nekomu o nekom, četudi tega ne bo videti ali slišati.

3. Tretje pravilo pravi, da moramo pri kodiranju opazovati vedenje tako, kot bi bilo naše. Vprašamo se, kako bi se sam počutil, če bi se tako vedel, ali tako govoril. Drug način je, da poskušamo posnemati oz. zrcaliti opazovano vedenje, kretnje ali besede in med tem opazujemo naše počutje.

\section{Sklep}

Naše prve izkušnje z uporabo prirejenega kodirnega sistema SPAFF so pokazale, da je težko kodirati napetost in strah, ki sta zelo pogosti, a verbalno neizraženi sestavini terapij, supervizij in terapevtskih treningov. Gre za čutenja, kot so zaskrbljenost, tesnoba, zadrega ali molk, ki so med seboj tesno povezana in za katera so značilne postopne spremembe v moči, bolj kot nenadno prenehanje ali izbruh. Ta problem je skoraj v celoti izginil, ko smo se odločili za uporabo več kod za eno samo osebo v eni sami sekvenci in ko je ocenjevalni tim sproti določil prag kodiranja. Taka rešitev je na drugi strani otežila izračun zanesljivosti, kar bomo predstavili v naših nadaljnjih objavah. Druga ugotovitev se nanaša na dolžino sekvenc, ki jih načeloma določimo glede na cilje raziskovanja in glede na količino 
razpoložljivega materiala. Pokazalo se je, da so bile krajše sekvence (od 15-30 sekund) primerne za čustvene procese, ki se spremenijo v eni sami uri (npr. terapevtovo izražanje sočutja in vzpostavitev stika, izražanje jeze in toleriranje sramu pri klientih), daljše (od 30-60 sekund) pa za procese, ki se spreminjajo bolj počasi, iz tedna $v$ teden ali iz meseca v mesec (npr. čustveno procesiranje spominov, razširitev palete čustvenih izrazov, regulacija strahu). Izbrana dolžina sekvenc seveda zelo približno odraža pogostost in trajanje posameznega čustva in nikakor ni ustrezen način za merjenje trajanja posameznega čustva, kakor ga pozna SPAFF. To pomanjkljivost bo potrebno $\mathrm{v}$ prihodnje odpraviti.

$\mathrm{V}$ prihodnje bo treba tudi preveriti veljavnost posameznih kod v sistemu, zlasti tistih, ki so prirejene (združitev veselje-humor, razdružitev napetost/strah) ali nove (sram, ranljivost). Heyman (2001) opozarja, da je konstrukcijsko veljavnost nekega kodirnega sistema potrebno preveriti po vsaki priredbi in da je zanesljivost sistema potrebno preveriti na ravni posameznih konstruktov in ne sistema kot celote. Dosedanje testiranje daje dovolj opore za oceno, da je prirejeni kodirni sistem lahko uporabno orodje za spremljanje čustvenih procesov $\mathrm{v}$ terapiji, pri čemer je potrebno prag kod vsakič znova $\mathrm{v}$ skladu s cilji raziskovanja prirediti kodiranemu materialu: sistem ima dovolj kod za opis terapevtovih posegov, dovolj kod za opis dogajanja med osebami, ki so prisotne na terapiji, ter fleksibilen postopek kodiranja, ki dopušča možnost, da se posamezno čustvo razvije in preoblikuje, kar je temeljna značilnost čustvenega procesiranja $\mathrm{v}$ terapiji.

\section{Literatura}

Butler, E. A., Egloff, B., Wilhelm, F. H., Smith, N. C., Erickson, E. A. in Gross, J. J. (2003). The social consequences of expressive suppression. Emotion, 3 , 48-67.

Cordova, J. V. in Dorian, M. (2004). Coding intimacy in couples' interactions. V P. K. Kerig in D. Baucom (ur.), Couple observational coding systems (str. 243256). Mahwah, NJ, ZDA: Lawrence Erlbaum.

Dorian, M., \& Cordova, J.V. (1999). The Intimacy Coding System. Neobjavljeni kodirni priročnik. University of Illinois, Urbana-Champaign.

Giese-Davis, J., Piemme, K. A., Dillon, C. in Twirbutt, S. (2005). Macro-variables in affective expression in women with breast cancer participating in support groups. V J. Harrigan, K. R. Scherer in R. Rosenthal (ur.), Nonverbal behavior in the affective sciences: A handbook of research methods (str. 399-445). Oxford, VB: Oxford University Press.

Floyd, F. J. in Markman, H. J. (1983). Observational biases in spousal observations: Toward a cognitivebehavioral model of marriage. Journal of Consulting and Clinical Psychology, 51, 450-457.

Gee, C. B., Scott, R. L., Castellani, A. M. in Cordova, J. V. (2002). Predicting 2-year marital satisfaction from partners' reaction to a marriage checkup. Journal of Marital and Family Therapy, 28, 399-408.
Gottman, J. M. (1979). Marital interaction: Experimental investigations. New York: Academic Press.

Gottman, J. M. (1999). The marriage clinic. New York, NY, ZDA: Norton.

Gottman, J., McCoy, K., Coan, J., \& Collier, H. (1995). The specific affect coding system (SPAFF) for observing emotional communication in marital and family interaction. V J. Gottman (ur.), What Predicts Divorce: The Measures. Mahway, NJ: Eribaum.

Gottman, J. M. in Coan, J. A. (2007). The specific affect coding system (SPAFF). V J. A. Coan and J. J. B. Allen (ur.), Handbook of Emotion Elicitation and Assessment (str. 106-123). New York, NY, ZDA: Oxford University Press.

Gottman, J. M., Coan, J., Carrere, S. in Swanson, C. (1998). Predicting marital happiness and stability from newlywed interactions. Journal of Marriage and the Family, 60(1), 5-22.

Greenberg, L. (2008). Emotion and cognition in psychotherapy: The transforming power of affect. Canadian Psychology/Psychologie canadienne, 49(1), 49-59.

Heyman, R. E. (2001). Observation of couple conflicts: Clinical assessment applications, stubborn truths, and shaky foundations. Psychological Assessment, 13, 5-35.

Heyman, R.E. in Vivian, D. (2000). Rapid Marital Interaction Coding System manual. Sneto 12.06.2011 s spletne strani www.psy.sunysb.edu/marital

Jacobson, N. S. in Moore, D. (1981). Spouses as observers of the events in their relationship. Journal of Consulting and Clinical Psychology, 49(2), 269-277.

Johnson, M. D. (2002). The observation of specific affect in marital interactions: Psychometric properties of a coding system and a rating system. Psychological Assessment, 14(4), 423-38.

Johnson, S. M. in Greenman, P. S. (2006). The path to a secure bond: Emotionally focused couple therapy. Journal of Clinical Psychology: In Session, 62(5), 597-609.

Kahng, S., in Iwata, B. A. (1998). Computerized systems for collecting real-time observational data. Journal of Applied Behavior Analysis, 31, 253-261.

Rožič, T., Torkar, M., Erzar, T. in Kompan Erzar, L. K. (2010). Dinamika sramu in ranljivosti v partnerskih odnosih in terapevtski potencial vpogleda v vzajemno afektivno dinamiko. Bogoslovni vestnik, 70(3), 415-429.

Stern, D. (2004). The Present moment in psychotherapy and everyday life. New York, NY, ZDA: W.W. Norton \& Company.

Whelton, W. J. (2004). Emotional processes in psychotherapy: Evidence across therapeutic modalities. Clinical Psychology and Psychotherapy, $11,58-71$.

Whelton, W. J. in Greenberg, L. S. (2005). Emotion in selfcriticism. Personality and Individual Differences, 38, 1583-1595.

Prispelo/Received: 7.3 .2012

Sprejeto/Accepted: 19.1.2013 